\title{
Erratum to: CT accuracy of percutaneous versus open pedicle screw techniques: a series of 1609 screws
}

\author{
Todd M. Chapman ${ }^{1}$ - Daniel J. Blizzard ${ }^{2}$ - Charles Sheets ${ }^{3} \cdot$ Christopher R. Brown $^{2}$
}

Published online: 12 October 2015

(c) Springer-Verlag Berlin Heidelberg 2015

\section{Erratum to: Eur Spine J}

\section{DOI 10.1007/s00586-015-4163-z}

There was an error in the order of author names.

One author Charles Sheets was missing. The correct order of author names is:

Todd M. Chapman, Daniel J. Blizzard, Charles Sheets, Christopher R. Brown.

Mr. Sheets' affiliation is:

Department of Physical and Occupational Therapy, Duke University Health System, Durham, NC, USA.

The online version of the original article can be found under doi:10.1007/s00586-015-4163-z.

Daniel J. Blizzard

daniel.blizzard@duke.edu

1 Department of Orthopaedic Surgery, Washington University

School of Medicine, St. Louis, MO, USA

2 Department of Orthopaedic Surgery, Duke University Medical Center, Durham, NC, USA

3 Department of Physical and Occupational Therapy, Duke University Health System, Durham, NC, USA 